\title{
The development of a low-cost laser communication system for the classroom
}

Robert Sparks, Stephen Pompea, Constance Walker

Robert T. Sparks, Stephen M. Pompea, Constance E. Walker, "The development of a low-cost laser communication system for the classroom," Proc. SPIE 9665, Tenth International Topical Meeting on Education and Training in Optics and Photonics, 96650N (3 June 2007); doi: $10.1117 / 12.2207498$

SPIE Event: Tenth International Topical Meeting on Education and Training in Optics and Photonics, 2007, Ottawa, Ontario, Canada 


\title{
The Development of a Low-Cost Laser Communication System for the Classroom
}

\author{
Robert T. Sparks, Stephen M. Pompea ${ }^{1}$ and Constance E. Walker ${ }^{1}$ \\ ${ }^{I}$ National Optical Astronomy Observatory, Tucson, Arizona, 85719 USA
}

\begin{abstract}
Hands-On Optics (HOO) is a National Science Foundation funded program to bring optics education to underserved middle school students. We have developed the culminating module (Module 6) on laser communication. Students learn how lasers can be modulated to carry information. The main activity of this module is the construction of a low-cost laser communication system. The system can be built using parts readily available at a local electronics store for approximately US \$60. The system can be used to transmit a person's voice or music from sources such as an mp3 player or radio over a distance of 350 feet. We will provide detailed plans on how to build the system in this paper.
\end{abstract}

\section{Introduction}

The Hands-On Optics project is a four-year informal science program is designed to bring the excitement of light, color, and optics technology to tens of thousands of underserved middle school-aged students nationwide. The HOO project ${ }^{1}$ has developed six hands-on activity modules intended to engage and enrich the math/science learning experience for students in the middle grades. Each module offers six to seven hours of exploratory science activities that can be grouped into 30- to 90-minute sessions. The project is aimed at after-school, museum, and science center settings but can be adapted for the formal education classroom.

Module 6 focuses on laser communication. The first activity addresses laser light illustrating the differences between white light and monochromatic light as well as coherent light and incoherent light. The second activity lets the students explore using light to transmit data in the form of Morse Code. The students then learn how to build the laser communication system. The students are given the challenge to communicate over the longest distance possible using the largest number of optical devices. The module culminates with a demonstration of fiber optics.

The problem we encountered with this module was the cost of the laser communication system. Companies such as Arbor Scientific ${ }^{2}$ sell ready-made laser communication kits. The kit consists of a 0.8mW Helium-Neon laser ( $\left.\$ 475\right)$ and a Laser Voice Transmission Package (\$139) consisting of a microphone, an amplified speaker, and a small photocell. The total price of $\$ 614$ was too costly for use in our kits, necessitating the development of a lower cost system. Other laser communication systems have been described by Thomas Petruzzellis ${ }^{3}$ and Gordon McComb ${ }^{4}$ Although these systems are robust, the circuits are more complicated and above the abilities of middle school students to construct them.

\section{The Low-Cost Communication System}

Conducting a web search led to a potential solution to the problem. We found a posting on ihacked.com ${ }^{5}$ by Simon Quellen Field. He described a technique using an audio output transformer from Radio Shack ${ }_{\circledast}$ to modulate a standard laser pointer. We designed a system around this concept. Our design was modified quite a bit during our testing to optimize its performance.

For our receiver, we used the same receiver as the NASA SOFIA Active Astronomy Infrared Kit ${ }^{6}$. The receiver

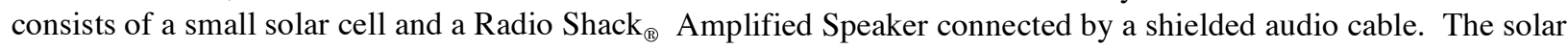
cell is very sensitive, and the system has been extensively tested by teachers in educational settings.

Tenth International Topical Meeting on Education and Training in Optics and Photonics, edited by Marc Nantel, Proc. of SPIE Vol. 9665, 96650N · (c) 2007 SPIE, OSA, IEEE, ICO doi: $10.1117 / 12.2207498$ 
The transmitter was more problematic. The original design used a laser pointer wired to an external battery pack. In order to make the transmitter easier to assemble, we decided to use a clip-activated laser pointer. You can insert this laser into a circuit simply by attaching a wire to the clip and a second wire to the laser body.

An amplified sound source is required to modulate the laser. We found that an MP3 player or CD player would work. However, we wanted the students to be able to transmit their own voice. Two solutions were found. The first is a device called the Gossip Gizmo from Radio Shack ${ }_{\circledast}$. The Gossip Gizmo (catalog \# 63-1121) is a small amplified microphone. Unfortunately, the Gossip Gizmo is difficult to obtain in large quantities. The second microphone we tried was the Pocket Size Stereo Amplified Listener (catalog \# 33-1096). It should be noted that although this microphone gives good performance with the laser communication system, the resulting transmission is not in stereo.

The other piece of the circuit is an audio output

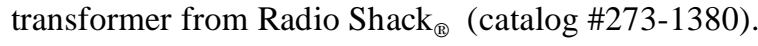
The audio output transformer is an $8 \Omega$ to $1000 \Omega$ transformer. The $1000 \Omega$ side has an extra wire called a center tap. The center tap is connected to the transformer halfway through the coils.

To assemble the receiver, the solar cell is connected to the amplified speaker. We have used a shielded audio cable with tinned leads and test leads to make the connection as shown in Figure 1.

To hook up the circuit, connect the microphone to the $8 \Omega$ side of the resistor. The laser is connected to the center tap of the $1000 \Omega$ side of the resistor and one of the end wires. One of the wires is connected to the laser's clip and one is connected to the laser's body. For the wire connected to the clip, be sure it does not accidentally

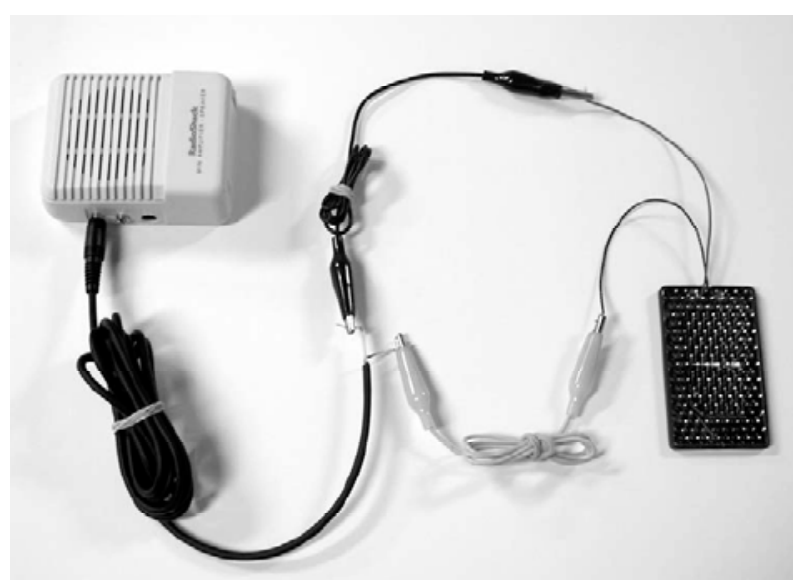

Figure 1: The receiver unit (photo courtesy the SOFIA project) touch the laser body and create a short circuit (you will not damage the laser, but it will not modulate and the system will not work).

Point the laser at the solar cell. Turn on the sound amplifier. Speak into the sound amplifier. If you hear a highpitched squeal, you are getting feedback. Turn down the sound amplifier. This system is very sensitive. If the laser is close to the solar cell, you will need to have the volume on the amplifier set very low to avoid feedback.

A circuit diagram for the set up is shown in Figure 2.

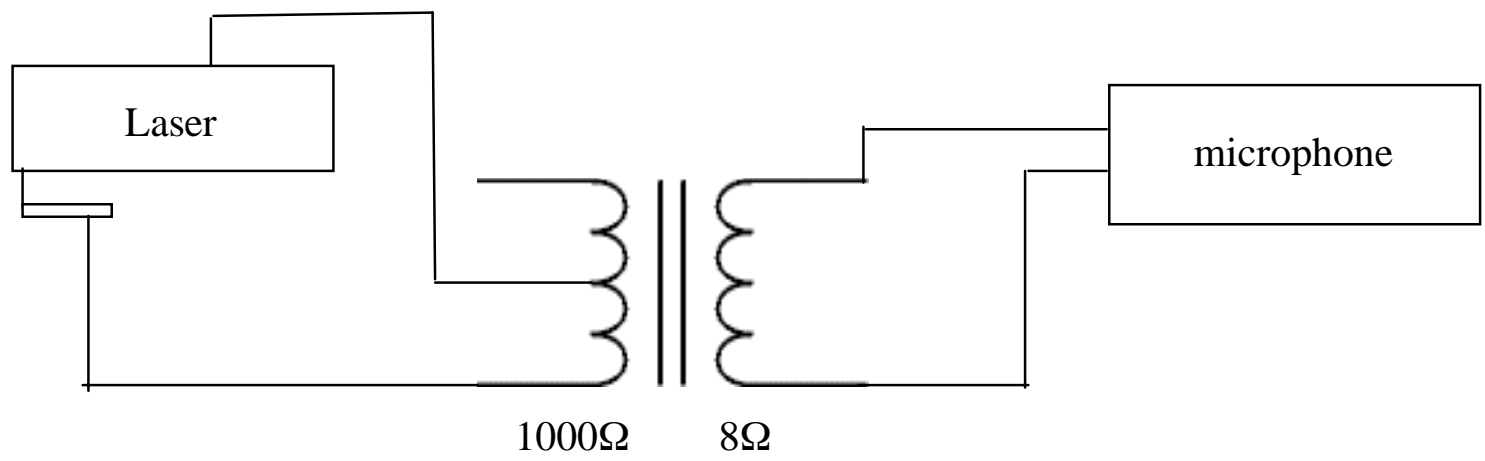

Figure 2: A circuit diagram for the transmitter. 


\subsection{Further Development of the Laser Communication System}

Julia Nichols, an undergraduate student in the University of Arizona College of Optical Sciences, was tasked with simplifying the connections for the laser communication system. She mounted the solar cell on the side of a small plastic box and connected the wires to a 1/8" jack on the side of the box. This setup allows a simple audio cable to connect the receiver to the speaker/amplifier. She devised a similar system for the transmitter. The audio output transformer is mounted inside a small plastic case. A 1/8" jack connects to the microphone. A small piece of copper cladding is connected to the audio output transformer. The circuit is completed by sliding the laser and its clip around the copper cladding as shown in Figure 3.

This system eliminates the alligator clips. The alligator clips frequently would come off the wires, especially in student use.

The new system is being manufactured by Green Valley Electronics in Tucson.

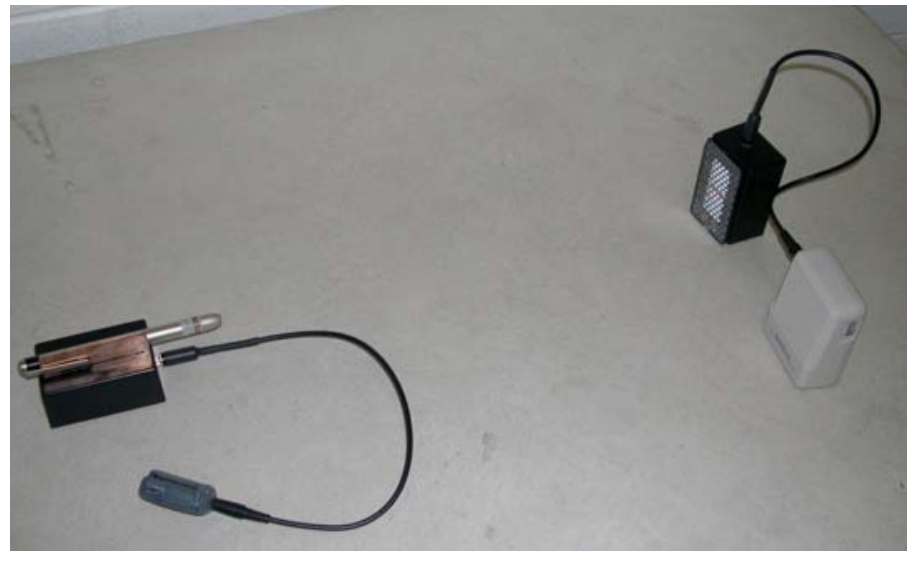

Figure 3: The new communication system

\section{Performance}

The laser communication system has been tested in a variety of lighting conditions. It does not need a dark room and will work in full sunlight. The system has a range of over 350 feet.

The beam will diverge noticeably as the distance traveled increases. Eventually the beam is too dim to see. However, the solar cell may still pick up the beam and produce sound from the speaker even when the beam has diverged beyond the point where it is visible.

We have not had any laser failures or problems with the modulator. The solar cell is somewhat delicate and should not be dropped.

\section{Classroom Use}

We have been experimenting with competitions where students attempt to communicate over the longest possible distance. They receive points for the distance traveled, reflections off of mirrors, and use of lenses in the system. The competition allows students to use some of the skills they learned in previous modules and apply them to laser communications. Our use of competitions to foster learning in optics is described in a previous ETOP paper ${ }^{7}$.

The basic concepts of reflection must be used to direct the beam when it reflects off of mirrors. Reflections are necessary as the range of the system is much longer than can be accommodated in classrooms. As the beam diverges, you can use lenses to focus the beam onto the solar cell, extending the range of the transmitter. One group of teachers at a workshop even used a filled water bottle as a convex lens to focus the beam.

We have also tested the system using a Vernier Lab Pro ${ }^{8}$ and light sensor. We used the light sensor to measure the intensity of the beam as a function of time, much like an oscilloscope. You could clearly see the intensity of the beam rising and falling. We also did some Fourier transforms of different waveforms and they looked the same as they would coming from a conventional microphone.

\section{Conclusion}

We have created a robust laser communication kit with high educational value. It has proved to be popular with students and has encouraged the problem-solving/challenge atmosphere we desire for our Hands-On Optics modules. The kit is inexpensive and can be assembled with easily available items. Most importantly, the kit provides the opportunity for high-quality open-ended experimentation by students on laser communication. This exploration of a modern, important technology is especially valuable as it provides a means to apply most of the optics concepts already explored in earlier Hands-On Optics modules. 
Appendix: List of Parts and Suppliers

\begin{tabular}{|c|c|c|c|c|}
\hline Item & Price & QNTY & Part \# & Source \\
\hline Laser Pointer & $\$ 15.95$ & 1 & $\begin{array}{l}\text { Infiniter } \\
\text { Super NBK } \\
\text { with Clip } \\
\text { Activation }\end{array}$ & store.greenpearle.com \\
\hline Speaker/Amplifier & $\$ 12.00$ & 1 & $277-1008$ & $\begin{array}{l}\text { Radio Shack }_{\circledast} \\
\text { www.radioshack.com }\end{array}$ \\
\hline $\begin{array}{l}6 \mathrm{ft} \text { shielded audio } \\
\text { cable }\end{array}$ & $\$ 2.99$ & 2 & $42-2371$ & $\begin{array}{l}\text { Radio Shack }_{\circledast} \\
\text { www.radioshack.com }\end{array}$ \\
\hline Test Leads & $\$ 0.52$ & 6 & $278-1156$ & $\begin{array}{l}\text { Radio Shack }_{\circledast} \\
\text { www.radioshack.com }\end{array}$ \\
\hline $\begin{array}{l}\text { Audio Output } \\
\text { Transformer }\end{array}$ & $\$ 2.99$ & 1 & $273-1380$ & $\begin{array}{l}\text { Radio Shack }_{\circledast} \\
\text { www.radioshack.com }\end{array}$ \\
\hline $\begin{array}{l}\text { Listen Up Sound } \\
\text { Amplifier }\end{array}$ & $\$ 9.99$ & 1 & 63-1121 & $\begin{array}{l}\text { Radio Shack }_{\circledast} \\
\text { www.radioshack.com }\end{array}$ \\
\hline Solar Cell & $\$ 6.00$ & 1 & $3-300$ & www.solarworld.com \\
\hline
\end{tabular}

All items in US \$

\section{References}

${ }^{1}$ S. M. Pompea, , A. Johnson, E. Arthurs and C. E. Walker . "Hands-On Optics: An Educational Initiative for Exploring Light and Color in After-School Programs, Museums, and Hands-On Science Centers”, Proceedings, Ninth International Topical Meeting on Education and Training in Optics and Photonics, Marseille, France 2005

${ }^{2}$ Arbor Scientific, PO Box 2750 Ann Arbor, MI 48106 (734) 477-9370 http://www.arborsci.com

${ }^{3}$ T. Preruzzellis, Optoelectronics, Fiber Optics and Laser Cookbook, McGraw-Hill, 1997

${ }^{4}$ G. McComb, Lasers, Ray Guns and Light Cannons, McGraw-Hill, 1997

${ }^{5}$ http://www.i-hacked.com/content/view/162/44/

${ }^{6}$ SOFIA Infrared Astronomy Kit is available from Astronomical Society of the Pacific 390 Ashton Avenue San Francisco, CA 94112 (415) 337-1100

${ }^{7}$ S. M. Pompea, C. E. Walker, and C. Peruta, "Design and Evaluation of Optics Student Competitions and Contests for Maximal Educational Value”, Proceedings, Ninth International Topical Meeting on Education and Training in Optics and Photonics, Marseille, France, 2005.

${ }^{8}$ Vernier Software \& Technology 13979 SW Millikan Way Beaverton, OR 97005-2886 888.837.6437

http://www.vernier.com 